\title{
Early intraoperative iron-binding proteins are associated with acute kidney injury after cardiac surgery
}

Nora Choi, MSc, ${ }^{\text {a,b }}$ Reid Whitlock, BSc, ${ }^{\mathrm{c}}$ Jessica Klassen, MD, ${ }^{\mathrm{d}}$ Michael Zappitelli, MD,

Rakesh C. Arora, MD, ${ }^{\mathrm{f}}$ Claudio Rigatto, MD, ${ }^{\mathrm{c}, \mathrm{d}, \mathrm{g}}$ and Julie Ho, MD ${ }^{\mathrm{a}, \mathrm{b}, \mathrm{d}}$

\section{ABSTRACT}

Objectives: Iron regulation is an important modifier of renal ischemiareperfusion injury, but the role of iron-binding proteins during cardiopulmonary bypass remains unclear. The goal was to characterize iron-binding proteins throughout ischemia-reperfusion injury to determine their association with acute kidney injury development.

Methods: A prospective observational cohort of adult patients who underwent cardiac surgery $(\mathrm{n}=301)$ was obtained, and acute kidney injury was defined by Kidney Disease Improving Global Outcomes. Serum ferritin, transferrin saturation, and urine hepcidin-25 were measured.

Results: Intraoperative serum ferritin was lower at the start of cardiopulmonary bypass $(P=.005)$ and 1 -hour cardiopulmonary bypass $(P=.001)$ in patients with acute kidney injury versus patients without acute kidney injury. Lower serum ferritin and higher transferrin saturation at 1-hour cardiopulmonary bypass were independent predictors of acute kidney injury (serum ferritin odds ratio, 0.66; $95 \%$ confidence interval $[\mathrm{CI}], 0.48-0.91$; transferrin saturation odds ratio, 1.26; $95 \%$ CI, 1.02-1.55) and improved model discrimination (area under the curve [AUC], 0.76; 95\% CI, 0.67-0.85) compared with clinical prediction alone (AUC, $0.72 ; 95 \% \mathrm{CI}, 0.62-0.81 ; \Delta \mathrm{AUC}$ and net reclassification index, $P=.01$ ). Lower ferritin, higher transferrin saturation at 1-hour cardiopulmonary bypass, and lower urine hepcidin-25 at postoperative day 1 were also independent predictors for acute kidney injury development, and this model demonstrated an AUC of 0.80 (0.72-0.87), which was superior to clinical prediction $(\triangle \mathrm{AUC} P=.002$, integrated discrimination improvement and net reclassification index $P=.003$ ).

Conclusions: Our findings suggest that lower levels of intraoperative iron-binding proteins may reflect an impaired capacity to rapidly handle catalytic iron released during cardiopulmonary bypass, leading to kidney injury. These data highlight the importance of iron homeostasis in human ischemia-reperfusion injury and suggest it is a potentially modifiable risk during cardiac surgery. Intraoperative detection of incipient acute kidney injury may be feasible and could be used as an enrichment strategy for clinical trials. (J Thorac Cardiovasc Surg 2019;157:287-97)

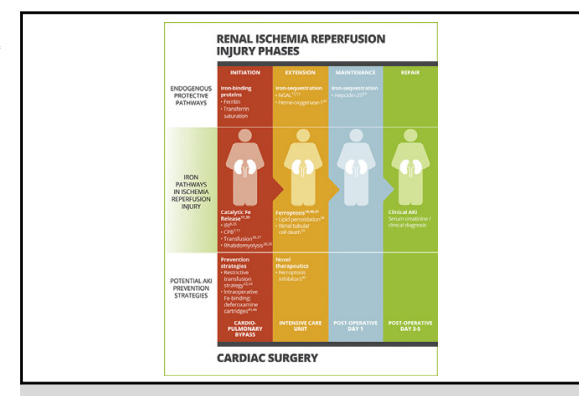

Proposed role of iron-binding proteins during cardiac surgery-related renal IRI and AKI.

\section{Central Message}

Lower intraoperative iron-binding proteins are inversely associated with postoperative AKI development, suggesting an impaired capacity to rapidly handle free iron release during $\mathrm{CPB}$ leading to AKI.

\section{Perspective}

There are no specific therapies for AKI, and limited human data exist on the early initiating events. These data highlight the importance of iron homeostasis during renal IRI and suggest it is a potentially modifiable risk factor during cardiac surgery. Intraoperative detection of incipient AKI may be feasible with routine clinical assays and could be used as an enrichment strategy for novel AKI trials.

See Editorial Commentary page 298

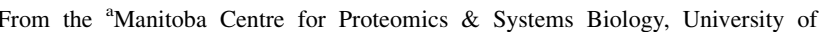
Manitoba, Winnipeg, Manitoba, Canada; ${ }^{b}$ Department of Immunology, University of Manitoba, Winnipeg, Manitoba, Canada; ${ }^{\mathrm{c} D e p a r t m e n t}$ of Community Health Sciences, University of Manitoba, Winnipeg, Manitoba, Canada; ${ }^{\mathrm{d} S e c t i o n}$ of Nephrology, Department of Internal Medicine, University of Manitoba, Winnipeg, Manitoba, Canada; ${ }^{\mathrm{e}}$ Division of Nephrology, Department of Pediatrics, Toronto Hospital for Sick Children, University of Toronto, Toronto, Ontario, Canada; ${ }^{\mathrm{f}}$ Department of Surgery, University of Manitoba, Winnipeg, Manitoba, Canada; and ${ }^{\mathrm{g}}$ Chronic Disease Innovation Centre, Seven Oaks Hospital, Winnipeg, Manitoba, Canada.

The prospective observational cohort of adult patients undergoing cardiac surgery was collected with funding support by Research Manitoba (J.H.). These analyses were funded by The Kidney Foundation of Canada (J.H.), Canadian Institutes of Health Research (J.H.), and Christella I Cann award (J.H., M.Z.). J.H. holds a Canadian Institutes of Health Research New Investigator Salary Award.
}

The results presented in this article have not been published previously in whole or part, except in abstract format. University of Manitoba Health Research Ethics Approval: HS15221; H2012:097, April 20, 2012

N.C., R.W., and J.K. contributed equally.

Received for publication Feb 7, 2018; revisions received June 23, 2018; accepted for publication June 28, 2018; available ahead of print Sept 6, 2018.

Address for reprints: Julie Ho, MD, Sections of Nephrology \& Biomedical Proteomics, Departments of Internal Medicine \& Immunology, University of Manitoba, GE421C Health Sciences Center, 820 Sherbrook St, Winnipeg, MB R3A 1R9, Manitoba, Canada (E-mail: jho@hsc.mb.ca).

0022-5223

Copyright (C) 2018 by The American Association for Thoracic Surgery. This is an open access article under the CC BY-NC-ND license (http://creativecommons.org/ licenses/by-nc-nd/4.0/).

https://doi.org/10.1016/j.jtcvs.2018.06.091 

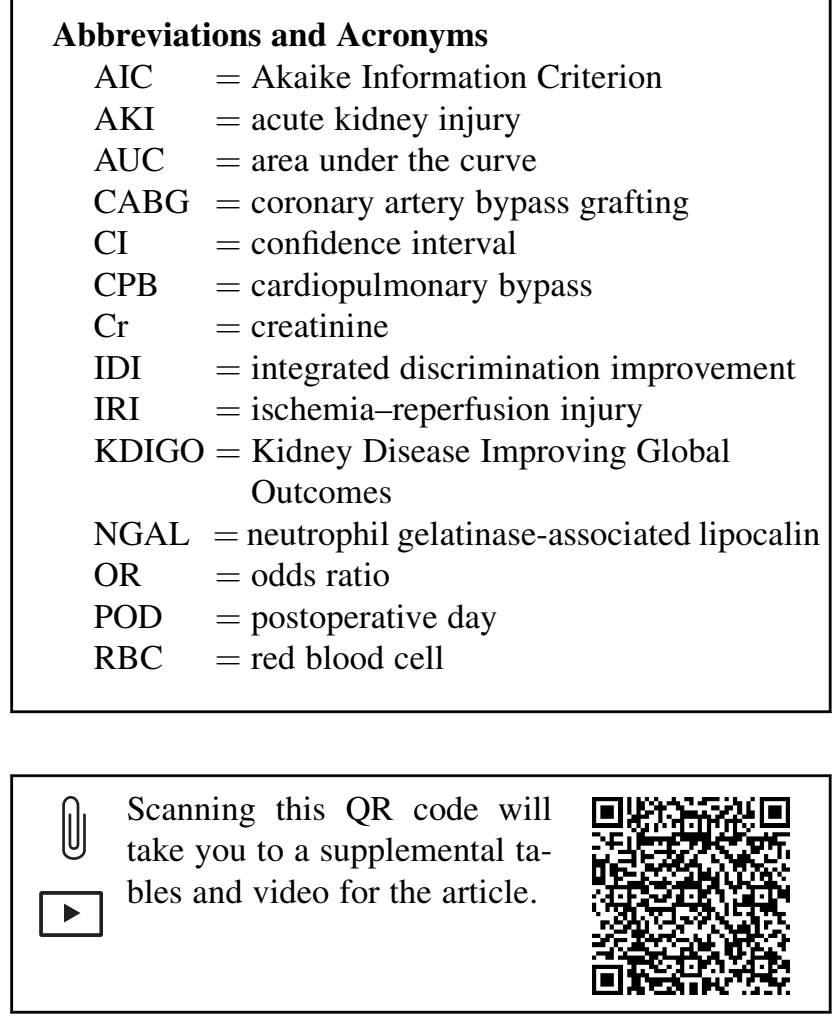

An improved understanding of the human physiologic responses to renal ischemia-reperfusion injury (IRI) may help develop novel approaches to management. Furthermore, tools that identify incipient renal injury before loss of function may be useful to facilitate early therapeutic intervention for acute kidney injury (AKI) and could be used as an enrichment strategy for clinical trials evaluating novel AKI therapeutics. ${ }^{1}$ To facilitate early identification, preoperative clinical risk prediction models have been developed to predict the need for renal replacement therapy after cardiac surgery. ${ }^{2}$ The Cleveland Clinic Score (Thakar score) is a well-validated model ${ }^{3}$ that predicts AKI and dialysis after cardiac surgery. ${ }^{4,5}$ However, few studies have evaluated intraoperative AKI markers during IRI, and these only reported poor to modest intraoperative discrimination, without demonstrating added value on preoperative clinical prediction. ${ }^{6}$

Free iron release is a common consequence of cardiopulmonary bypass (CPB), resulting in increased circulating iron and oxidative stress. ${ }^{7}$ Iron regulatory pathways play a role in the development of postcardiac surgery $\mathrm{AKI},{ }^{7-9}$ and indeed, ferroptosis is a key mediator of IRI-related renal tubular cell death. ${ }^{10}$ Markers of these processes, such as plasma catalytic iron and plasma free hemoglobin, are elevated intraoperatively and associated with postoperative AKI development. ${ }^{7,11}$ However, the intraoperative response to free iron release remains incompletely characterized. Neutrophil gelatinaseassociated lipocalin (NGAL) and urine hepcidin-25 are both iron-sequestering proteins associated with human AKI development and are renoprotective when administered in animal models of AKI. ${ }^{8,9,12-16}$ However, both NGAL and urine hepcidin- 25 peak postoperatively, with only modest intraoperative AKI discrimination (intraoperative urine and plasma NGAL area under the curve [AUC], 0.59 and 0.64 , respectively). ${ }^{15-19}$

Because nephrotoxic catalytic iron release occurs during $\mathrm{CPB}$, we hypothesized that an expanded capacity for iron binding or sequestration would be inversely associated with AKI development and may act as early markers of incipient AKI development. Therefore, the goal of this study was to evaluate intraoperative serum ferritin and transferrin saturation during renal IRI to determine their association with AKI development in a prospective observational cohort of adult patients who underwent cardiac surgery.

\section{MATERIALS AND METHODS}

The study protocol was approved by the University of Manitoba institutional review board, and all patients provided written informed consent (Ethics Approval HS15221; H2012:097). The funding agency had no role in the study design, data analysis, or manuscript preparation. All elective coronary artery bypass graft (CABG) or valve replacement operations requiring CPB at St Boniface Hospital from June 2012 to October 2014 were considered for inclusion. Exclusion criteria included off-pump surgeries, preexisting dialysis dependence or renal transplant, deceased before surgery, canceled/delayed surgeries, and missed urine or serum bio-banking. Patient demographics and comorbidities were abstracted from patient charts and the Manitoba Cardiac Surgery Database. Intraoperative and postoperative data collection included duration of the operation, total $\mathrm{CPB}$ and aortic crossclamp time, urine output, blood pressure, inotrope support, blood products, and potential nephrotoxic exposures (aminoglycoside, nonsteroidal anti-inflammatory agents, angiotensin-converting enzyme inhibitors, angiotensin receptor blockers, and contrast).

\section{Primary Outcome}

Baseline serum creatinine $(\mathrm{Cr})$ was established using an average of the 2 most recent preoperative serum creatinine values for all patients. AKI was defined using the 2012 Kidney Disease Improving Global Outcomes (KDIGO) criteria: serum $\mathrm{Cr}$ increase greater than $50 \%$ from baseline or $0.3 \mathrm{mg} / \mathrm{dL}$ or more increase within 48 hours. ${ }^{20}$ The KDIGO urine output criterion was not applied to determine AKI. ${ }^{21}$

\section{Primary Exposure Variables of Interest}

The Cleveland Clinic Score, or Thakar score, was used as a base clinical risk prediction model for $\mathrm{AKI} .{ }^{3}$ Serum samples obtained immediately after the start of $\mathrm{CPB}$ and 1-hour CPB (intraoperative) were analyzed for ferritin and transferrin saturation. Intraoperative serum ferritin was measured using the Cobas e601/e602 Roche Analyzer (Basel, Switzerland), iron was measured using the Cobas C702 Roche Analyzer, total iron-binding capacity was measured using the Ortho Vitros 4600 (Raritan, NJ) in the clinical laboratory, and transferrin saturation $(\%)$ was calculated. Urine hepcidin-25 at POD 1 was measured with a competitive enzyme-linked immunosorbent assay (Penlab S-1337) (Biotek Synergy 4 microplate reader, Gen 5 software, Fisher Scientific, Waltham, Mass), as previously described. ${ }^{16,22}$ 


\section{Statistical Analyses}

All data were analyzed using SAS Version 9.3 (SAS Institute, Inc, Cary, NC). Continuous variables are presented as median (interquartile range) and compared using the Mann-Whitney $U$ test. Categoric variables are presented as frequency (percentage) and compared with the chi-square test. Logistic regression was used to assess the univariate association of patient characteristics with postoperative AKI. Two multivariable logistic regression models of clinical prediction with intraoperative iron-handling biomarkers (intraoperative model and postoperative model) were assessed for their ability to predict postoperative AKI and compared with the base clinical prediction model (Thakar score alone). The intraoperative model included the Thakar score, intraoperative serum ferritin, and transferrin saturation at 1-hour $\mathrm{CPB}$. The postoperative model included the Thakar score, intraoperative serum ferritin, and transferrin saturation at 1-hour CPB, and urine hepcidin-25 at POD 1 . We examined the discrimination and goodness-of-fit for each model by calculating the area under the curve (AUC), Hosmer-Lemeshow test, and Akaike information criterion (AIC). The AIC was generated to determine the balance between goodness-of-fit and model complexity and to allow for model quality comparison. Each enriched model was compared with the base clinical model (Thakar score alone) to examine improvement in discrimination ( $\triangle \mathrm{AUC}$, integrated discrimination improvement [IDI]) and reclassification (Net Reclassification Index). Spearman's rank correlation coefficients $(\rho)$ were calculated between each of the predictor variables. Multicollinearity was assessed using a multiple linear regression model. Two variables were considered highly correlated if $|\rho|$ was greater than .7 and collinear if the variance inflation factor was more than 10 .

\section{RESULTS}

\section{Prospective Observational Cohort}

A total of 380 adult patients who underwent cardiac surgery were enrolled in the prospective observational cohort. Twenty-one patients were excluded for off-pump surgeries $(\mathrm{n}=3)$, preexisting dialysis dependence $(\mathrm{n}=3)$, deceased before surgery $(\mathrm{n}=1)$, and canceled/delayed surgeries $(n=14)$. Fifty-eight patients were excluded for missed serum and urine bio-banking, resulting in a final prospective observational cohort of 40 patients with AKI and 261 patients without AKI $(\mathrm{n}=301)$ (Figure 1). The study population characteristics are reported in Table 1, and there were no differences in the characteristics of the final study population $(\mathrm{n}=301)$ versus those excluded for missed bio-banking $(\mathrm{n}=58)$ (Table E1).

\section{Intraoperative Serum Ferritin Is Inversely Associated With Acute Kidney Injury}

Intraoperative serum ferritin and transferrin saturation at the start of CPB and 1-hour CPB were compared in those with and without AKI. Serum ferritin at the start of CPB and 1 hour into CPB was lower in AKI versus non-AKI $(P=.005$ and $P=.001$, respectively). Serum transferrin saturation at the start of $\mathrm{CPB}$ and 1 hour into $\mathrm{CPB}$ was similar in AKI and non-AKI (Figure 2).

\section{Univariate Predictors of Acute Kidney Injury}

Clinical variables associated with AKI development included preoperative Modified Diet in Renal Disease estimated glomerular filtration rate, baseline $\mathrm{Cr}$, diabetes mellitus, congestive heart failure, higher Thakar score, lower preoperative hemoglobin, and total amount of intraoperative red blood cell (RBC) transfusions (Table 2). It is notable that patients without AKI had a higher preoperative $\mathrm{Hb}(P<.001)$, and patients without AKI had a higher transfusion requirement $(P<.001)$; these data were significantly correlated $(\mathrm{R}-0.41)$, suggesting that individuals with lower preoperative $\mathrm{Hb}$ were more likely to require blood transfusion. CPB pump time was not a univariate predictor of AKI $(P=.094)$. Intraoperative and postoperative blood pressures and inotrope requirement were not associated with AKI development in this cohort. Only 1 patient received contrast dye postoperatively, and therefore meaningful analysis could not be conducted.

Intraoperative serum ferritin was inversely associated with AKI, with higher levels associated with a lower likelihood of developing AKI (start CPB: odds ratio [OR], $0.62 ; 95 \%$ confidence interval $[\mathrm{CI}], 0.44-0.86 ; P=.005$; 1-hour CPB: OR, $0.62 ; 95 \% \mathrm{CI}, 0.45-0.84 ; P=.002$ ). As previously reported in this cohort, postoperative day (POD) 1 urine hepcidin-25 was inversely associated with AKI development (OR, 0.62; 95\% CI, 0.45-0.85; $P=.002) .{ }^{22}$ Serum transferrin saturation at 1 -hour $\mathrm{CPB}$ showed only a trend to association with postoperative AKI $(P=.07)$ (Table 2).

\section{Iron-Sequestering Proteins Are Multivariable Predictors of Acute Kidney Injury}

A preoperative base clinical model using the Thakar score was established for AKI prediction (OR, 1.62; 95\% CI, 1.34-1.96; $P<.001)$. The intraoperative model (Thakar score, serum ferritin, and transferrin saturation) demonstrated that serum ferritin and transferrin saturation at 1-hour CPB predicted postoperative AKI, after adjusting for preoperative clinical prediction (serum ferritin OR, $0.66 ; 95 \% \mathrm{CI}, 0.48-0.91 ; P=.012$ and transferrin saturation $\mathrm{OR}, 1.26 ; 95 \% \mathrm{CI}, 1.02-1.55 ; P=.035)$ (Table 3). Because sources of free iron from hemolysis may contribute to AKI, total intraoperative $\mathrm{RBC}$ transfusions and CPB pump time were added to the intraoperative model, but neither were significant multivariable predictors of AKI (RBC transfusions OR, 1.13 ; $95 \%$ CI, $0.94-1.35 ; P=.21$ and CPB pump time OR, $1.25 ; 95 \%$ CI, $0.85-1.83 ; P=.26$ ). Preoperative hemoglobin was not a significant multivariable predictor of postoperative AKI development $(P=.158)$. Because different iron-sequestering proteins may be linked by the same causal pathways, we next sought to determine if urine hepcidin-25 was an independent predictor of AKI. The postoperative model (Thakar score, serum ferritin and transferrin saturation, urine hepcidin-25) demonstrated that urine hepcidin-25 remained an independent predictor of AKI (OR, 0.68; 95\% CI, 0.48-0.95; $P=.026$ ) (Table 3). 


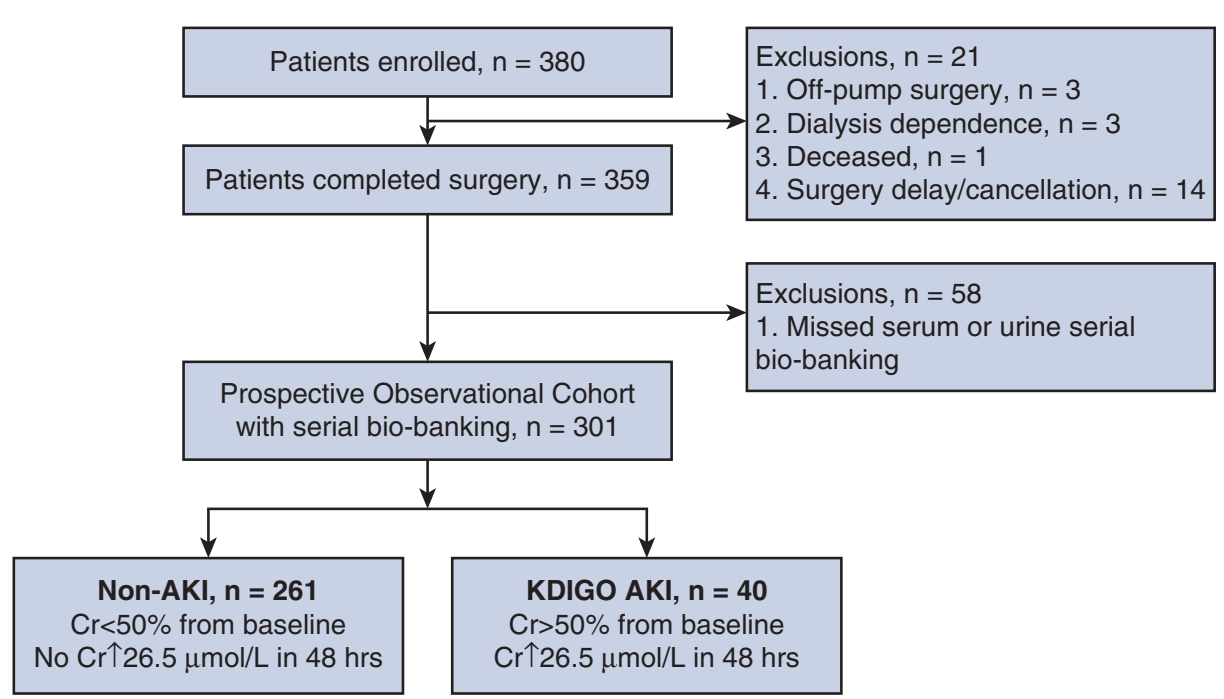

FIGURE 1. Prospective observational cohort of adult patients undergoing cardiac surgery, $\mathrm{n}=301$. AKI, Acute kidney injury; $C r$, creatinine; KDIGO, Kidney Disease Improving Global Outcomes.

\section{Discrimination of Iron-Sequestering Proteins for Acute Kidney Injury}

The base clinical prediction model (Thakar score) demonstrated good discrimination (AUC, $0.72 ; 95 \%$ CI, 0.62-0.81) with better discrimination in the intraoperative model (Thakar score, serum ferritin, and transferrin saturation) compared with clinical prediction alone (AUC, $0.76 ; 95 \%$ CI, 0.67-0.85). Further improvement in discrimination was seen with the postoperative model (Thakar score, serum ferritin and transferrin saturation, urine hepcidin-25) (AUC, 0.80; 95\% CI, 0.72-0.87), with a sensitivity and specificity of 0.78 and 0.63 , respectively. The sequential addition of iron-sequestering proteins improved the overall quality of the model as demonstrated by the lower AIC for intraoperative and postoperative models compared with the base model $(200.0,195.1$ vs 213.5) (Table 4). The sensitivities and specificities of intraoperative and postoperative models are presented over a range of cutoffs (Table E2).

\section{Intraoperative Iron-Sequestering Proteins Improve Preoperative Clinical Prediction}

The intraoperative model (Thakar score, serum ferritin, and transferrin saturation) demonstrated improvement on base clinical prediction as measured by the absolute difference in AUC and IDI $(P=.011$ and $P=.011$, respectively), but not by Net Reclassification Index $(P=.25)$. Furthermore, the postoperative model (Thakar score, serum ferritin and transferrin saturation, urine hepcidin-25) demonstrated superior model discrimination relative to clinical prediction alone, and by a higher margin than enriched model 1, measured by both absolute difference in AUC and by IDI ( $\triangle \mathrm{AUC} 0.08,95 \% \mathrm{CI}$, $0.03-0.13, P=.002$; IDI $0.10,95 \%$ CI, $0.03-0.17$,
$P=.003)$. The postoperative model was also more likely to correctly reclassify subjects (Net Reclassification Index $0.50,95 \%$ CI, 0.18-0.82, $P=.003$ ) (Table 5).

\section{Sensitivity Analyses}

Because serum ferritin, serum transferrin saturation, and urinary hepcidin-25 are all markers of iron-binding or sequestration, we sought to determine if they were highly correlated. A correlation matrix was generated that demonstrated these variables were not highly correlated and none were collinear. Therefore, no decision was taken to remove any variables from the models (Table E3).

To identify early predictors of AKI, we excluded patients who developed AKI before the measurement of serum ferritin and transferrin saturation at 1-hour CPB and urine hepcidin-25 at POD 1.

Intraoperative serum $\mathrm{Cr}$ was measured in all patients, and no patients developed intraoperative AKI. Six patients developed KDIGO AKI before POD 1; therefore, the multivariable analysis for the postoperative model was repeated on adjusted prospective observational cohort $(n=295)$. Serum ferritin and urine hepcidin-25 remained independent predictors of postoperative AKI; however, serum transferrin saturation did not. The overall model still showed good AKI prediction with AUC 0.81 (0.73-0.87) (Table E4) (Video 1).

\section{DISCUSSION}

The principal finding of this study is that serum ferritin, transferrin saturation, and urine hepcidin- 25 are each predictors of subsequent AKI development. The independent association of lower serum ferritin, lower urine hepcidin25, and elevated transferrin saturation with AKI suggests that different iron regulatory pathways may be activated in response to IRI to collectively mitigate the impact of 
TABLE 1. Study population characteristics, $n=301$

\begin{tabular}{|c|c|c|c|}
\hline Characteristic & Non-AKI $(n=261)$ & $\operatorname{AKI}(n=40)$ & $P$ value \\
\hline \multicolumn{4}{|l|}{ Preoperative } \\
\hline Age (y) & $66(60-71)$ & $70(63-75)$ & .044 \\
\hline Male & $198(76 \%)$ & $27(68 \%)$ & .26 \\
\hline Baseline eGFR $\left(\mathrm{mL} / \mathrm{min} / 1.73 \mathrm{~m}^{2}\right)$ & $82(66-96)$ & $62(42-77)$ & $<.001$ \\
\hline Baseline $\mathrm{Cr}(\mathrm{mg} / \mathrm{dL})$ & $84(72-100)$ & $102(85-143)$ & $<.001$ \\
\hline Preoperative hemoglobin $(\mathrm{g} / \mathrm{L})$ & $140(128-151)$ & $120(109-134)$ & $<.001$ \\
\hline Thakar score & $2(1-3)$ & $3(2-5)$ & $<.001$ \\
\hline Diabetes mellitus & $76(29 \%)$ & $25(63 \%)$ & $<.001$ \\
\hline Chronic obstructive pulmonary disease & $22(8 \%)$ & $2(5 \%)$ & .75 \\
\hline Congestive heart failure & $21(8 \%)$ & $10(25 \%)$ & .006 \\
\hline Previous myocardial infarction & $97(37 \%)$ & $12(30 \%)$ & .38 \\
\hline Previous $\mathrm{CABG}$ & $7(3 \%)$ & $2(5 \%)$ & .34 \\
\hline Peripheral arterial disease & $19(7 \%)$ & $6(15 \%)$ & .099 \\
\hline Previous cerebrovascular accident & $12(5 \%)$ & $4(10 \%)$ & .24 \\
\hline Previous transient ischemic attack & $9(3 \%)$ & $1(3 \%)$ & .76 \\
\hline \multicolumn{4}{|l|}{ Intraoperative } \\
\hline Type of surgery (isolated CABG) & $165(63 \%)$ & $23(58 \%)$ & .49 \\
\hline Total RBC transfusion (units) & $0(0-0)$ & $0.5(0-2)$ & $<.001$ \\
\hline Pump time (min) & $94(73-130)$ & $98(82-147)$ & .11 \\
\hline Crossclamp time (min) & $64(45-90)$ & $62(45-96)$ & .57 \\
\hline Operating room duration (min) & $258(218-336)$ & $266(207-355)$ & .98 \\
\hline Intraoperative urine output (mL) & $640(445-970)$ & $525(453-853)$ & .24 \\
\hline Serum ferritin start CPB $(\mu \mathrm{g} / \mathrm{L})$ & $142(87-264)$ & $78(46-176)$ & .005 \\
\hline Serum ferritin 1 h CPB $(\mu \mathrm{g} / \mathrm{L})$ & $180(110-315)$ & $100(60-200)$ & .001 \\
\hline Serum iron $(\mu \mathrm{mol} / \mathrm{L})$ & $11(9-14)$ & $10(8-13)$ & .38 \\
\hline $\mathrm{TIBC}(\mu \mathrm{mol} / \mathrm{L})$ & $35(32-39)$ & $34(31-38)$ & .74 \\
\hline Transferrin saturation start CPB (\%) & $28(21-37)$ & $24(20-41)$ & .19 \\
\hline Transferrin saturation $1 \mathrm{~h} \mathrm{CPB} \mathrm{( \% )}$ & $31(24-40)$ & $28(23-41)$ & .59 \\
\hline \multicolumn{4}{|l|}{ Postoperative day 1} \\
\hline Urine hepcidin-25 ( $\mu \mathrm{g} / \mathrm{L})$ & $1568(686-2733)$ & $623(152-1803)$ & $<.001$ \\
\hline Urine hepcidin-25: $\mathrm{Cr}(\mu \mathrm{g} / \mathrm{mmoL})$ & $120(64-208)$ & $63(23-130)$ & .002 \\
\hline
\end{tabular}

Values expressed as median (interquartile range) or frequency (percent). eGFR calculated using the Modification of Diet in Renal Disease equation. AKI, Acute kidney injury; $e G F R$, estimated glomerular filtration rate; $C r$, creatinine; $C A B G$, coronary bypass graft; $R B C$, red blood cell; $C P B$, cardiopulmonary bypass; $T I B C$, total iron-binding capacity.

catalytic iron release on $\mathrm{CPB}$, which is known to be an inciting factor for AKI. ${ }^{8,9}$ It is notable that these intraoperative iron-binding proteins improved on preoperative clinical AKI prediction, and this discrimination improved further with the addition of urine hepcidin25 at POD 1; each preceded clinical AKI detection using serum $\mathrm{Cr}$. Therefore, these data also suggest that intraoperative detection of incipient AKI may be feasible using readily available clinical assays.

Ferritin is an iron-binding protein found in intracellular and extracellular compartments and is capable of sequestering up to 4500 iron atoms intracellularly until required for metabolic processes. ${ }^{23}$ Furthermore, ferritin is composed of $\mathrm{H}$ and $\mathrm{L}$ subunits that play a role in converting the oxidative state of reactive ferrous iron $\left(\mathrm{Fe}^{2+}\right)$ to the ferric form $\left(\mathrm{Fe}^{3+}\right)$, via ferroxidase activity. ${ }^{24}$ In a pilot study $(\mathrm{n}=30)$, Davis and colleagues ${ }^{25}$ demonstrated that lower preoperative serum ferritin was associated with increased AKI development, but these findings were not confirmed in a larger prospective observational cohort study $(\mathrm{n}=120) .{ }^{26}$ Conversely, Leaf and colleagues ${ }^{11}$ found that increased serum ferritin on POD 1 is associated with dialysis requirement or death. We expanded these findings by demonstrating that low intraoperative serum ferritin and elevated transferrin saturation are independent predictors for AKI during the initiation phase of IRI and speculate that the kinetics of ferritin elevation observed by Leaf and colleagues on POD 1 reflects an acute phase response concurrent with the extension phase of AKI. ${ }^{11,27,28}$ Although it is possible that changes in intraoperative ferritin reflect an acute phase response, ${ }^{29}$ it is unlikely to explain our findings because increased intraoperative ferritin was observed in patients without AKI, whereas increased inflammation would have been anticipated in patients with AKI.

Transferrin is an iron-binding transport protein, and under physiologic conditions approximately $30 \%$ of its binding sites are occupied. Transferrin saturation increases with elevated iron levels as additional binding 

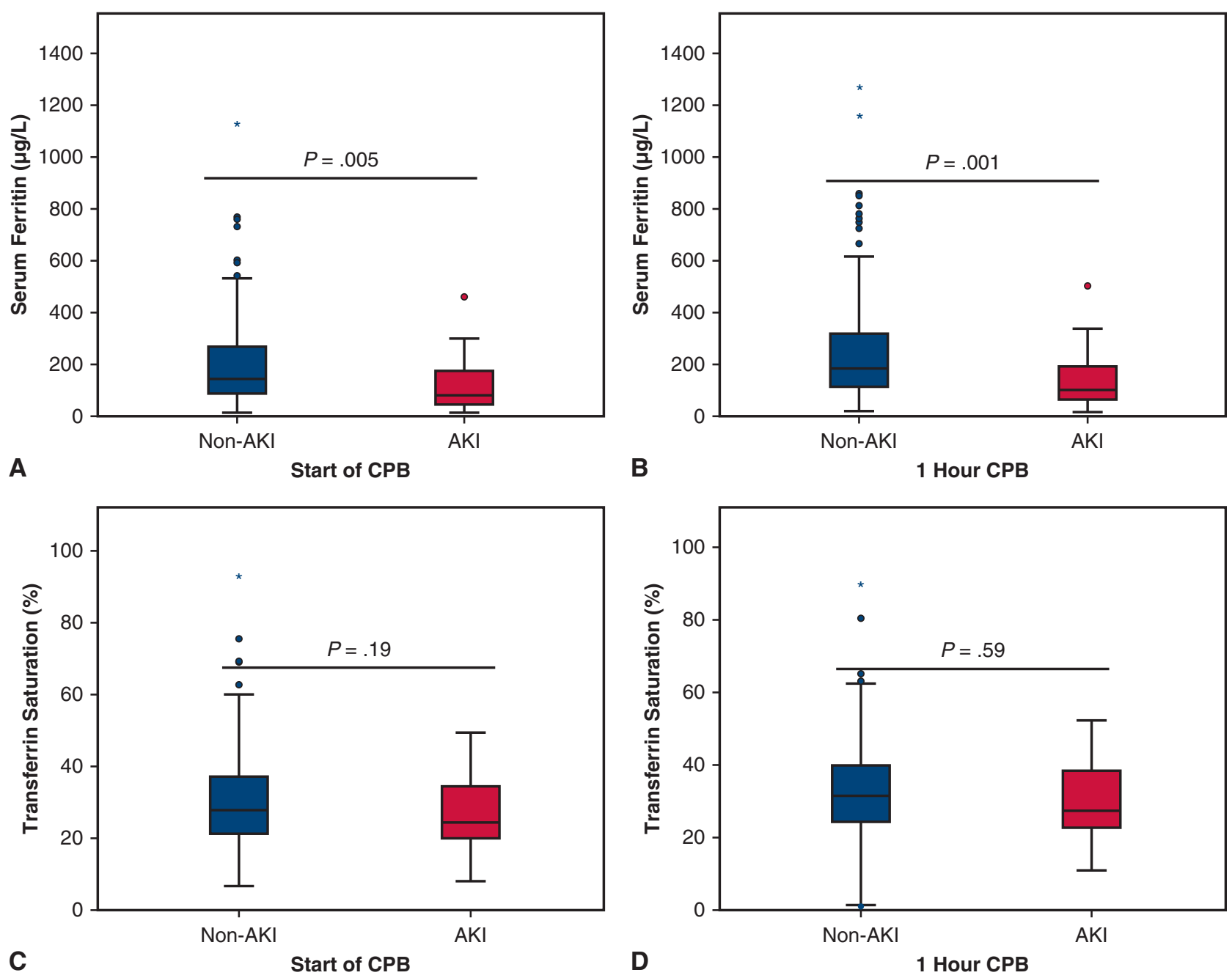

FIGURE 2. Intraoperative serum ferritin and transferrin saturation in patients with $\mathrm{AKI}$ versus without $\mathrm{AKI}$ at the start of CPB and 1 hour on $\mathrm{CPB}$. Lower serum ferritin was associated with those with AKI at $(\mathrm{A})$ start of $\mathrm{CPB}(P=.005)$ and $(\mathrm{B}) 1$-hour $\mathrm{CPB}(P=.001)$. No difference in transferrin saturation between patients with $\mathrm{AKI}$ and patients without $\mathrm{AKI}$ at both start of $\mathrm{CPB}$ and 1-hour CPB. $P=.19(\mathrm{C})$ and $P=.59$ (D). Box plots demonstrate horizontal median line between 25th and 75th percentiles. The upper and lower whiskers represent the minimum and maximum values of nonoutliers, and dots represent outliers. $C P B$, Cardiopulmonary bypass.

sites become occupied. We anticipated that transferrin saturation would increase between the start and 1 hour on $\mathrm{CPB}$ as free iron is released during $\mathrm{CPB}^{11,30}$; however, this was not the case. This 1-hour window may have been insufficient to observe a significant increase in transferrin saturation, and indeed peak catalytic iron release has been observed at the end of CPB. ${ }^{11}$ Nevertheless, increased transferrin saturation was an independent predictor for AKI development, and this may reflect an early adaptive response to minimize the effects of IRI by sequestering free iron. ${ }^{10}$

Urine hepcidin-25 was inversely associated and an independent predictor of AKI. ${ }^{15,16,31,32}$ Urine hepcidin-25 was evaluated at POD 1, because it has been shown to have low intraoperative levels. ${ }^{15,16}$ Hepcidin-25 indirectly regulates circulating iron by degrading ferroportin, the only known iron exporter located predominantly on hepatocytes, macrophages, and enterocytes. ${ }^{33}$ Because of the inverse association of urinary hepcidin- 25 and the development of postcardiac surgery AKI, we have speculated that it is an endogenous renoprotective mechanism through sequestering catalytic free iron release during CPB ${ }^{15,16,34}$ Exogenously administered hepcidin has been shown to be highly protective in murine models of renal IRI and hemoglobin-mediated AKI, with a significant reduction in tubular injury, apoptosis, renal oxidative stress, and inflammation, and improved renal function. ${ }^{8,9}$ Notably, Scindia and colleagues ${ }^{8}$ observed that renal IRI increased serum iron and hepcidin levels independently of surgery, and this effect was mitigated by pretreatment with hepcidin. 
TABLE 2. Univariate predictors of postoperative acute kidney injury

\begin{tabular}{|c|c|c|c|}
\hline Characteristic & OR for AKI prediction & $95 \% \mathrm{CI}$ & OR $P$ value \\
\hline \multicolumn{4}{|l|}{ Preoperative } \\
\hline Age (y) & 1.03 & $0.99-1.06$ & .129 \\
\hline Male & 0.66 & $0.32-1.36$ & .26 \\
\hline Baseline eGFR $\left(\mathrm{mL} / \mathrm{min} / 1.73 \mathrm{~m}^{2}\right)$ & 0.96 & $0.94-0.97$ & $<.001$ \\
\hline Baseline $\mathrm{Cr}(\mathrm{mg} / \mathrm{dL})$ & 1.02 & $1.01-1.03$ & $<.001$ \\
\hline Preoperative hemoglobin $(\mathrm{g} / \mathrm{L})$ & 0.95 & $0.94-0.97$ & $<.001$ \\
\hline Thakar score & 1.62 & $1.34-1.96$ & $<.001$ \\
\hline Diabetes mellitus & 4.06 & $2.03-8.12$ & $<.001$ \\
\hline Chronic obstructive pulmonary disease & 0.57 & $0.13-2.53$ & .75 \\
\hline Congestive heart failure & 3.76 & $1.63-8.82$ & .006 \\
\hline Previous myocardial infarction & 0.73 & $0.35-1.49$ & .38 \\
\hline Previous CABG & 1.91 & $0.38-9.54$ & .34 \\
\hline Peripheral arterial disease & 2.25 & $0.84-6.02$ & .099 \\
\hline Previous cerebrovascular accident & 2.31 & $0.71-7.54$ & .24 \\
\hline Previous transient ischemic attack & 0.72 & $0.09-5.82$ & .76 \\
\hline \multicolumn{4}{|l|}{ Intraoperative } \\
\hline Type of surgery (isolated CABG) & 0.79 & $0.40-1.55$ & .49 \\
\hline Total RBC transfusion (units) & 1.27 & $1.07-1.50$ & .007 \\
\hline Pump time (min) & $1.36^{*}$ & $0.95-1.96$ & .094 \\
\hline Crossclamp time (min) & $1.05^{*}$ & $0.71-1.54$ & .82 \\
\hline Operating room duration (min) & $1.06^{*}$ & $0.87-1.27$ & .58 \\
\hline Intraoperative urine output $(\mathrm{mL})$ & $0.95 \dagger$ & $0.87-1.03$ & .192 \\
\hline Serum ferritin start CPB $(\mu \mathrm{g} / \mathrm{L})$ & $0.62 \ddagger$ & $0.44-0.86$ & .005 \\
\hline Serum ferritin $1 \mathrm{~h} \mathrm{CPB}(\mu \mathrm{g} / \mathrm{L})$ & $0.62 \ddagger$ & $0.45-0.84$ & .002 \\
\hline Serum iron $(\mu \mathrm{mol} / \mathrm{L})$ & 0.97 & $0.94-1.01$ & .116 \\
\hline $\operatorname{TIBC}(\mu \mathrm{mol} / \mathrm{L})$ & 1.01 & $0.96-1.06$ & .56 \\
\hline Transferrin saturation start CPB (\%) & $1.23 \S$ & $0.91-1.67$ & .176 \\
\hline Transferrin saturation $1 \mathrm{~h}$ CPB (\%) & $1.14 \S$ & $0.99-1.31$ & .073 \\
\hline \multicolumn{4}{|l|}{ Postoperative day 1} \\
\hline Urine hepcidin-25 $(\mu \mathrm{g} / \mathrm{L})$ & $0.62 \|$ & $0.45-0.85$ & .002 \\
\hline Urine hepcidin-25: $\mathrm{Cr}(\mu \mathrm{g} / \mathrm{mmoL})$ & $0.63 \rrbracket$ & $0.43-0.92$ & .015 \\
\hline
\end{tabular}

eGFR calculated using the Modification of Diet in Renal Disease equation. OR, Odds ratio; $A K I$, acute kidney injury; $C I$, confidence interval; $e G F R$, estimated glomerular filtration rate; $C r$, creatinine; $C A B G$, coronary artery bypass grafting; $R B C$, red blood cell; $C P B$, cardiopulmonary bypass; $T I B C$, total iron-binding capacity. $*$ Time (per 60 minutes).

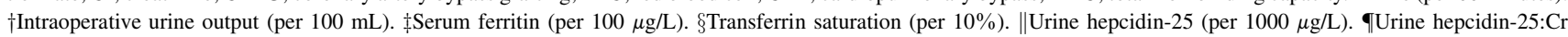
(per $100 \mu \mathrm{g} / \mathrm{mmoL}$ ).

These data suggest that hepcidin is increased secondary to iron homeostatic changes during IRI and is not strictly an inflammatory response to cardiac surgery.

Renal IRI alone results in elevated free iron levels, ${ }^{8,35}$ and this is further exacerbated during $\mathrm{CPB}$, which can weaken RBC structural integrity, increasing plasma free hemoglobin and catalytic iron release. ${ }^{11,30}$ Intraoperative transfusion of older blood with an RBC storage lesion can further contribute to hemolysis and elevated free iron. ${ }^{36}$ Indeed, older RBC transfusions are significantly associated with an increased risk of AKI after cardiac surgery. ${ }^{37}$ Of note, we found that RBC transfusions and CPB pump time were not significant independent predictors of AKI after accounting for serum ferritin and transferrin saturation. Unfortunately, we did not have data on the duration of RBC storage before transfusion to delineate the effect of the RBC storage lesion on AKI development in this cohort. $^{37}$
Tight iron regulation within a homeostatic range is critical, because there are no active excretion mechanisms for excess iron. ${ }^{24}$ Catalytic iron plays a key role in AKI development because it can participate in redox reactions to generate highly reactive hydroxyl radicals capable of oxidative damage and tubular lipid peroxidation, ${ }^{35}$ and it has been shown to be nephrotoxic in murine models of IRI, ${ }^{35}$ rhabdomyolysis, ${ }^{38}$ and hemoglobinuria. ${ }^{39}$ Ferroptosis is an iron-dependent form of regulated cell death that is characterized by tubular lipid peroxidation. ${ }^{40}$ Ferroptosis plays a key role during renal IRI and other animal models of AKI, ${ }^{10,41}$ and heme oxygenase- 1 is an endogenous ferroptosis inhibitor of renal proximal tubular epithelial cell death. ${ }^{42}$ Taken together, we speculate that the observed elevated ferritin and hepcidin-25, with lower transferrin saturation, in patients without AKI reflect an increased capacity to sequester iron to help mitigate the effects of catalytic iron release during initiation of AKI. The 
TABLE 3. Multivariable analyses of iron-sequestering proteins for acute kidney injury prediction, $n=301$

\begin{tabular}{llr}
\hline \multicolumn{1}{c}{ Model type } & OR $(\mathbf{9 5} \%$ CI $)$ & $\boldsymbol{P}$ value \\
\hline $\begin{array}{l}\text { Preoperative base clinical model } \\
\quad \text { Thakar score }\end{array}$ & $1.62(1.34-1.96)$ & $<.001$ \\
Intraoperative model & $1.62(1.33-1.98)$ & $<.001$ \\
$\quad$ Thakar score & $0.66(0.48-0.91)$ & .012 \\
$\quad$ Serum ferritin (per $100 \mu \mathrm{g} / \mathrm{L})$ & $1.26(1.02-1.55)$ & .035 \\
$\quad$ Transferrin saturation $($ per $10 \%)$ & & \\
Postoperative model & $1.51(1.23-1.85)$ & $<.001$ \\
$\quad$ Thakar score & $0.67(0.49-0.92)$ & .013 \\
$\quad$ Serum ferritin (per $100 \mu \mathrm{g} / \mathrm{L})$ & $1.34(1.06-1.69)$ & .014 \\
$\quad$ Transferrin saturation $($ per $10 \%)$ & .026 \\
$\quad$ Urine hepcidin-25 (per $1000 \mu \mathrm{g} / \mathrm{L})$ & $0.68(0.48-0.95)$ & .026 \\
\hline
\end{tabular}

Preoperative Base Clinical Model: Thakar score. Intraoperative Model: Thakar score $+1 \mathrm{~h} \mathrm{CPB}$ serum ferritin $+1 \mathrm{~h}$ CPB transferrin saturation. Postoperative Model: Thakar score $+1 \mathrm{~h} \mathrm{CPB}$ serum ferritin $+1 \mathrm{~h}$ CPB transferrin saturation + urine hepcidin-25. OR, Odds ratio; $C I$, confidence interval.

mechanism by which this renoprotective effect occurs may be mediated through inhibition of ferroptosis (Figure 3). Taken together, these findings support the importance of effective iron homeostatic mechanisms during CPB to rapidly adapt to a catalytic iron load.

Our study has potential clinical and research implications. Understanding the significant and modifiable factors in cardiac surgery-associated AKI offers insight into potential risk mitigation approaches. First, restrictive transfusion strategies have been demonstrated to be noninferior to liberal transfusion strategies for cardiac surgery. ${ }^{43,44}$ This suggests that a restrictive transfusion strategy may be optimal for renal outcomes after cardiac surgery, given its demonstrated safety and as an approach to limit catalytic free iron release. ${ }^{43,44}$ Second, our data highlight the importance of iron-binding or sequestration as an independent and potentially modifiable risk in human

TABLE 4. Iron-sequestering proteins-diagnostic model performance

\begin{tabular}{|c|c|c|c|}
\hline Test & $\begin{array}{c}\text { Preoperative } \\
\text { base clinical } \\
\text { model }\end{array}$ & $\begin{array}{c}\text { Intraoperative } \\
\text { model }\end{array}$ & $\begin{array}{c}\text { Postoperative } \\
\text { model }\end{array}$ \\
\hline Global $P$ value & $<.001$ & $<.001$ & $<.001$ \\
\hline $\begin{array}{l}\text { Discrimination, } \\
\text { AUC } \\
(95 \% \mathrm{CI})\end{array}$ & $0.72(0.62-0.81)$ & $0.76(0.67-0.85)$ & $0.80(0.72-0.87)$ \\
\hline AIC & 213.5 & 200.0 & 195.1 \\
\hline $\begin{array}{l}\text { Goodness of fit* } \\
\quad(P \text { value })\end{array}$ & $2.76(0.60)$ & $11.41(0.180)$ & $15.09(0.057)$ \\
\hline Sensitivity & 0.63 & 0.53 & 0.78 \\
\hline Specificity & 0.75 & 0.92 & 0.63 \\
\hline \multicolumn{4}{|c|}{$\begin{array}{l}A U C \text {, Area under the curve; } C I \text {, confidence interval; } A I C \text {, akaike Information } \\
\text { Criterion. *Hosmer-Lemeshow test statistic. The maximum cutoff was used to } \\
\text { generate sensitivity and specificity. Preoperative Base Clinical Model: Thakar score. } \\
\text { Intraoperative Model: Thakar score }+1 \mathrm{~h} \mathrm{CPB} \text { serum ferritin }+1 \mathrm{~h} \mathrm{CPB} \text { transferrin } \\
\text { saturation. Postoperative Model: Thakar score }+1 \mathrm{~h} \mathrm{CPB} \text { serum ferritin }+1 \mathrm{~h} \mathrm{CPB} \\
\text { transferrin saturation + urine hepcidin- } 25 \text {. }\end{array}$} \\
\hline
\end{tabular}

TABLE 5. Model comparison of independent predictors of acute kidney injury

\begin{tabular}{lccc}
\hline $\begin{array}{l}\text { Intraoperative model vs } \\
\text { base clinical model }\end{array}$ & Value & $\mathbf{9 5} \% \mathbf{C I}$ & $\boldsymbol{P}$ value \\
\hline$\Delta$ AUC & 0.05 & $0.01-0.09$ & .011 \\
Net Reclassification Index & 0.20 & $-0.14-0.53$ & .25 \\
\hline IDI & 0.08 & $0.02-0.15$ & .011 \\
\hline $\begin{array}{l}\text { Postoperative model vs } \\
\text { base clinical model }\end{array}$ & Value & $\mathbf{9 5} \% \mathbf{C I}$ & $\boldsymbol{P}$ value \\
\hline$\Delta$ AUC & 0.08 & $0.03-0.13$ & .002 \\
Net Reclassification Index & 0.50 & $0.18-0.82$ & .003 \\
IDI & 0.10 & $0.03-0.17$ & .003 \\
\hline
\end{tabular}

Preoperative Base Clinical Model: Thakar score. Intraoperative Model: Thakar score $+1 \mathrm{~h} \mathrm{CPB}$ serum ferritin $+1 \mathrm{~h} \mathrm{CPB}$ transferrin saturation. Postoperative Model: Thakar score $+1 \mathrm{~h} \mathrm{CPB}$ serum ferritin $+1 \mathrm{~h}$ CPB transferrin saturation + urine hepcidin-25. $C I$, Confidence interval; $\triangle A U C$, change in area under the receiver operating characteristic; IDI, integrated discrimination improvement.

AKI. This suggests the intriguing possibility that extracorporeal removal of free iron during CPB may be useful to protect against AKI. Food and Drug Administration-approved cartridges with immobilized deferoxamine have been developed for use in series with dialysis to maximize the intra-dialytic removal of iron and aluminum $^{45}$ and are effective for clearing nontransferrin bound iron, ${ }^{46}$ and it is possible that these cartridges could be used in series with the CPB circuit. Although AKI pathophysiology is highly multifactorial in nature, targeted and minimally invasive interventions such as these may help to mitigate the effects of renal IRI.

\section{Study Strengths and Limitations}

Our study has several important strengths, including a rigorous prospective observational design, prospective and

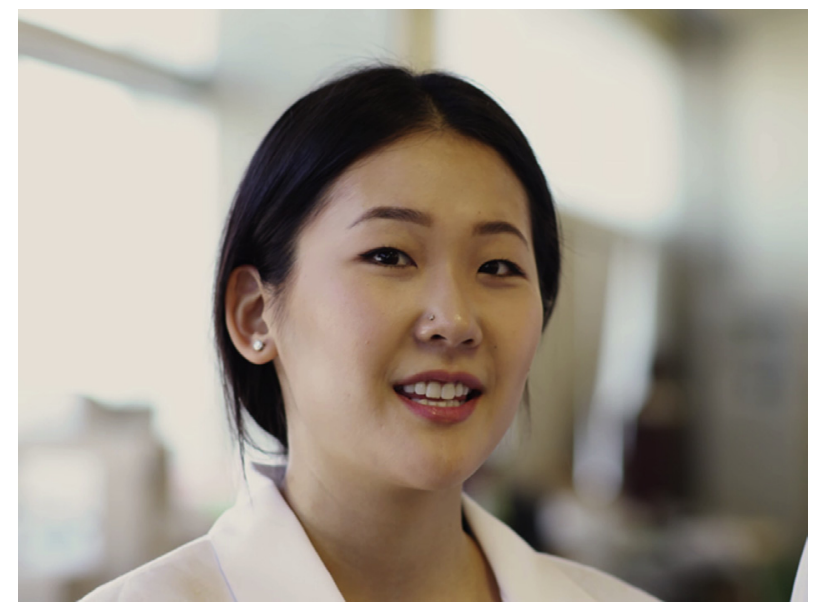

VIDEO 1. Intraoperative iron-binding proteins are associated with the development of postcardiac surgery AKI. Video available at: https:// www.jtcvs.org/article/S0022-5223(18)32021-X/fulltext. 


\section{RENAL ISCHEMIA REPERFUSION INJURY PHASES}

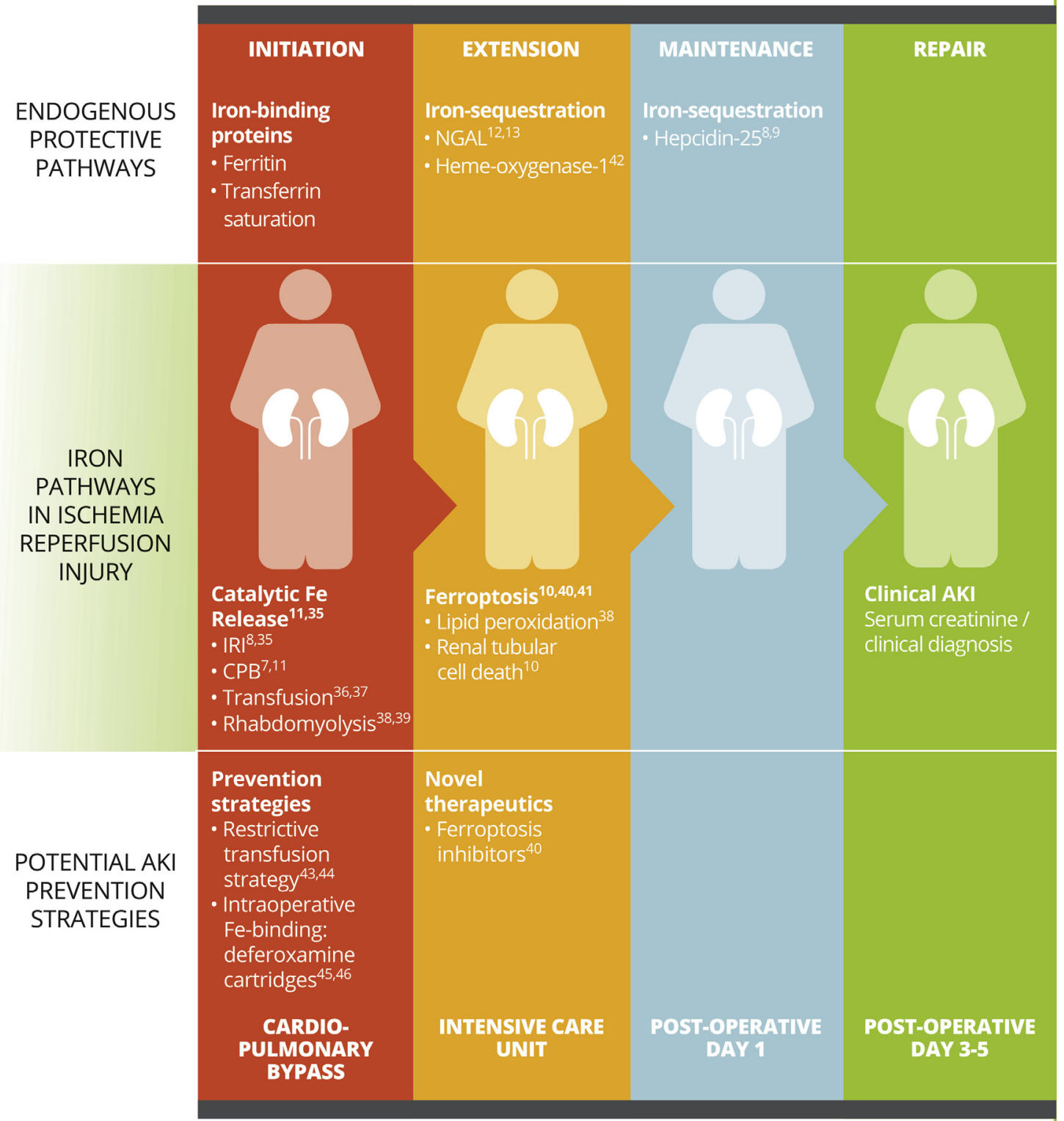

\section{CARDIAC SURGERY}

FIGURE 3. Phases of renal IRI during cardiac surgery with a proposed model for the role of iron-binding proteins. Intraoperative catalytic free iron release during IRI on CPB may cause renal tubular cell lipid peroxidation, which can lead to ferroptosis, a novel iron-dependent form of cell death in renal IRI/AKI (middle). Early intraoperative iron-binding proteins and postoperative iron-sequestering proteins may be endogenous renoprotective strategies that act to mitigate the impact of catalytic free iron release during CPB (top). The importance of maintaining iron homeostasis during cardiac surgery highlights the potential for minimally invasive, intraoperative AKI prevention strategies, and novel AKI therapeutics targeting these pathways (bottom). $N G A L$, Neutrophil gelatinase-associated lipocalin; IRI, ischemia-reperfusion injury; $C P B$, cardiopulmonary bypass; $A K I$, acute kidney injury. 
systematic intraoperative serum sampling, careful clinical characterization, and the use of a well-validated outcome definition for AKI. Our study also has some limitations that we acknowledge. Because this is a single-center observational cohort, validation in independent cohorts will be required. Our cohort included patients with low to intermediate Thakar scores (average 3 [2-5] for AKI and 2 [1-3] for patients without AKI). As such, we observed low rates of severe AKI and renal replacement therapy. Therefore, our results should be validated in higher-risk cohorts. These milder AKI phenotypes may have contributed to the modest intraoperative discrimination for postoperative AKI (AUC, 0.76). Nevertheless, these iron-binding proteins still outperformed previously reported intraoperative urine and plasma biomarker prediction for postoperative AKI. ${ }^{6}$ Finally, although these observational data led us to speculate that changes in serum ferritin, transferrin saturation, and hepcidin-25 identify distinct iron homeostatic mechanisms that may be renoprotective in human IRI, we cannot prove causation.

\section{CONCLUSIONS}

This study demonstrates that intraoperative serum ferritin and transferrin saturation are independently associated with the development of postoperative cardiac surgery AKI. Because serum ferritin, transferrin saturation, and urine hepcidin-25 are each independent predictors of AKI, this suggests that iron sequestration is a key and potentially modifiable factor in AKI. These data may help inform targeted and minimally invasive AKI prevention strategies. Clinical trials ultimately will be required to evaluate specific AKI interventions, and these data may be useful as an enrichment strategy to recruit patients at high risk of developing AKI. Indeed, early intraoperative detection of incipient AKI may be feasible using Food and Drug Administration-validated quantitative assays for serum ferritin and transferrin saturation, which are readily available in clinical laboratories.

\section{Conflict of Interest Statement}

R.C.A. reports a grant from Pfizer Canada Inc, and honoraria from Mallickrodt Pharmaceuticals outside the submitted work. J.H. reports grants from the Canadian Institutes of Health Research, The Kidney Foundation of Canada, Research Manitoba, and Christella I. Cann award, and speaker honoraria from Astellas Pharma outside the submitted work. All other authors have nothing to disclose with regard to commercial support.

The authors thank the Adult Cardiac Surgery Program at St Boniface Hospital and the operating room staff for their assistance with the collection of this cohort. The authors would also like to gratefully acknowledge the contributions of Segun Olude from Indigo Ink Studios for his assistance with graphic design.

\section{References}

1. Roy-Chaudhury P. Exploring novel endpoints for clinical trials in kidney disease: challenges and opportunities. Kidney Int Rep. 2017;2:295-6.

2. Kristovic D, Horvatic I, Husedzinovic I, Sutlic Z, Rudez I, Baric D, et al. Cardiac surgery-associated acute kidney injury: risk factors analysis and comparison of prediction models. Interact Cardiovasc Thorac Surg. 2015; $21: 366-73$

3. Thakar CV, Arrigain S, Worley S, Yared JP, Paganini EP. A clinical score to predict acute renal failure after cardiac surgery. J Am Soc Nephrol. 2005; 16: $162-8$.

4. Wong B, St Onge J, Korkola S, Prasad B. Validating a scoring tool to predict acute kidney injury (AKI) following cardiac surgery. Can J Kidney Health Dis. 2015;2:3.

5. Englberger L, Suri RM, Li Z, Dearani JA, Park SJ, Sundt TM III, et al. Validation of clinical scores predicting severe acute kidney injury after cardiac surgery. Am J Kidney Dis. 2010;56:623-31.

6. Ho J, Tangri N, Komenda P, Kaushal A, Sood M, Brar R, et al. Urinary, plasma, and serum biomarkers' utility for predicting acute kidney injury associated with cardiac surgery in adults: a meta-analysis. Am J Kidney Dis. 2015;66: 993-1005.

7. Vermeulen Windsant IC, Snoeijs MG, Hanssen SJ, Altintas S, Heijmans JH, Koeppel TA, et al. Hemolysis is associated with acute kidney injury during major aortic surgery. Kidney Int. 2010;77:913-20.

8. Scindia Y, Dey P, Thirunagari A, Liping H, Rosin DL, Floris M, et al. Hepcidin mitigates renal ischemia-reperfusion injury by modulating systemic iron homeostasis. J Am Soc Nephrol. 2015;26:2800-14.

9. van Swelm RP, Wetzels JF, Verweij VG, Laarakkers CM, Pertijs JC, van der Wijst J, et al. Renal handling of circulating and renal-synthesized hepcidin and its protective effects against hemoglobin-mediated kidney injury. J Am Soc Nephrol. 2016;27:2720-32.

10. Linkermann A, Skouta R, Himmerkus N, Mulay SR, Dewitz C, De Zen F, et al. Synchronized renal tubular cell death involves ferroptosis. Proc Natl Acad Sci U S A. 2014;111:16836-41.

11. Leaf DE, Rajapurkar M, Lele SS, Mukhopadhyay B, Rawn JD, Frendl $\mathrm{G}$, et al. Increased plasma catalytic iron in patients may mediate acute kidney injury and death following cardiac surgery. Kidney Int. 2015;87:1046-54

12. Mishra J, Mori K, Ma Q, Kelly C, Yang J, Mitsnefes M, et al. Amelioration of ischemic acute renal injury by neutrophil gelatinase-associated lipocalin. J Am Soc Nephrol. 2004;15:3073-82.

13. Mori K, Lee HT, Rapoport D, Drexler IR, Foster K, Yang J, et al. Endocytic delivery of lipocalin-siderophore-iron complex rescues the kidney from ischemia-reperfusion injury. J Clin Invest. 2005;115:610-21.

14. Mishra J, Ma Q, Prada A, Mitsnefes M, Zahedi K, Yang J, et al. Identification of neutrophil gelatinase-associated lipocalin as a novel early urinary biomarker for ischemic renal injury. J Am Soc Nephrol. 2003;14:2534-43.

15. Ho J, Lucy M, Krokhin O, Hayglass K, Pascoe E, Darroch G, et al. Mass spectrometry-based proteomic analysis of urine in acute kidney injury following cardiopulmonary bypass: a nested case-control study. Am J Kidney Dis. 2009;53: 584-95.

16. Ho J, Reslerova M, Gali B, Gao A, Bestland J, Rush DN, et al. Urinary hepcidin-25 and risk of acute kidney injury following cardiopulmonary bypass. Clin J Am Soc Nephrol. 2011;6:2340-6.

17. Han WK, Wagener G, Zhu Y, Wang S, Lee HT. Urinary biomarkers in the early detection of acute kidney injury after cardiac surgery. Clin J Am Soc Nephrol. 2009; 4:873-82.

18. Koyner JL, Bennett MR, Worcester EM, Ma Q, Raman J, Jeevanandam V, et al. Urinary cystatin $\mathrm{C}$ as an early biomarker of acute kidney injury following adult cardiothoracic surgery. Kidney Int. 2008;74:1059-69.

19. Perry TE, Muehlschlegel JD, Liu KY, Fox AA, Collard CD, Shernan SK, et al. Plasma neutrophil gelatinase-associated lipocalin and acute postoperative kidney injury in adult cardiac surgical patients. Anesth Analg. 2010;110: 1541-7.

20. Kidney Disease: Improving Global Outcomes (KDIGO) Acute Kidney Injury Work Group. KDIGO Clinical Practice Guideline for Acute Kidney Injury Kidney Int Suppl. 2012;2:1-138.

21. Md Ralib A, Pickering JW, Shaw GM, Endre ZH. The urine output definition of acute kidney injury is too liberal. Crit Care. 2013;17:R112.

22. Choi N, Rigatto C, Zappitelli M, Ang G, Christie S, Hiebert B, et al. Urinary hepcidin-25 elevation in patients that avoid acute kidney injury following cardiac surgery. Can J Kidney Health Dis. 2018;5:1-9. 
23. Orino K, Lehman L, Tsuji Y, Ayaki H, Torti SV, Torti FM. Ferritin and the response to oxidative stress. Biochem J. 2001;357(Pt 1):241-7.

24. Wang J, Pantopoulos K. Regulation of cellular iron metabolism. Biochem J. 2011;434:365-81.

25. Davis CL, Kausz AT, Zager RA, Kharasch ED, Cochran RP. Acute renal failure after cardiopulmonary bypass in related to decreased serum ferritin levels. J Am Soc Nephrol. 1999;10:2396-402.

26. Tuttle KR, Worrall NK, Dahlstrom LR, Nandagopal R, Kausz AT, Davis CL. Predictors of ARF after cardiac surgical procedures. Am J Kidney Dis. 2003; 41:76-83.

27. Rosner MH, Okusa MD. Acute kidney injury associated with cardiac surgery. Clin J Am Soc Nephrol. 2006;1:19-32.

28. Ho J, Dart A, Rigatto C. Proteomics in acute kidney injury-current status and future promise. Pediatr Nephrol. 2014;29:163-71.

29. Paparella D, Yau TM, Young E. Cardiopulmonary bypass induced inflammation: pathophysiology and treatment. An update. Eur J Cardiothorac Surg. 2002;21: 232-44.

30. Haase M, Bellomo R, Haase-Fielitz A. Novel biomarkers, oxidative stress, and the role of labile iron toxicity in cardiopulmonary bypass-associated acute kidney injury. J Am Coll Cardiol. 2010;55:2024-33.

31. Prowle JR, Ostland V, Calzavacca P, Licari E, Ligabo EV, Echeverri JE, et al. Greater increase in urinary hepcidin predicts protection from acute kidney injury after cardiopulmonary bypass. Nephrol Dial Transplant. 2012;27:595-602.

32. Haase-Fielitz A, Mertens PR, Plass M, Kuppe H, Hetzer R, Westerman M, et al. Urine hepcidin has additive value in ruling out cardiopulmonary bypass-associated acute kidney injury: an observational cohort study. Crit Care. 2011;15:R186.

33. Ganz T, Nemeth E. Hepcidin and iron homeostasis. Biochim Biophys Acta. 2012; 1823:1434-43.

34. Choi N, Rigatto C, Zappitelli M, Gao A, Christie S, Hiebert B, et al. Urinary hepcidin-25 is elevated in patients that avoid acute kidney injury following cardiac surgery. Can J Kidney Health Dis. 2018;5. 2054358117744224.

35. Baliga R, Ueda N, Shah SV. Increase in bleomycin-detectable iron in ischaemia/reperfusion injury to rat kidneys. Biochem J. 1993;291(Pt 3):901-5.
36. Kim-Shapiro DB, Lee J, Gladwin MT. Storage lesion: role of red blood cel breakdown. Transfusion. 2011;51:844-51.

37. Koch CG, Li L, Sessler DI, Figueroa P, Hoeltge GA, Mihaljevic T, et al. Duration of red-cell storage and complications after cardiac surgery. $N$ Engl J Med. 2008 358:1229-39.

38. Baliga R, Zhang Z, Baliga M, Shah SV. Evidence for cytochrome P-450 as a source of catalytic iron in myoglobinuric acute renal failure. Kidney Int. 1996; 49:362-9.

39. Paller MS. Hemoglobin- and myoglobin-induced acute renal failure in rats: role of iron in nephrotoxicity. Am J Physiol. 1988;255(3 Pt 2):F539-44.

40. Stockwell BR, Friedmann Angeli JP, Bayir H, Bush AI, Conrad M, Dixon SJ, et al. Ferroptosis: a regulated cell death nexus linking metabolism, redox biology, and disease. Cell. 2017;171:273-85.

41. Martin-Sanchez D, Ruiz-Andres O, Poveda J, Carrasco S, Cannata-Ortiz P, Sanchez-Nino MD, et al. Ferroptosis, but not necroptosis, is important in nephrotoxic folic acid-induced AKI. J Am Soc Nephrol. 2017;28:218-29.

42. Adedoyin O, Boddu R, Traylor AM, Lever JM, Bolisetty S, George J, et al. Heme oxygenase-1 mitigates ferroptosis in renal proximal tubule cells. Am J Physiol Renal Physiol. 2018;314:F702-14.

43. Mazer CD, Whitlock RP, Fergusson DA, Hall J, Belley-Cote E, Connolly K, et al. Restrictive or liberal red-cell transfusion for cardiac surgery. N Engl J Med. 2017; 377:2133-44.

44. Murphy GJ, Pike K, Rogers CA, Wordsworth S, Stokes EA, Angelini GD, et al Liberal or restrictive transfusion after cardiac surgery. N Engl J Med. 2015;372: 997-1008.

45. Anthone S, Ambrus CM, Kohli R, Min I, Anthone R, Stadler A, et al. Treatment of aluminum overload using a cartridge with immobilized desferrioxamine. J Am Soc Nephrol. 1995;6:1271-7.

46. Ambrus CM, Stadler I, Toumbis CA, Stadler A, Anthone S, Anthone R, et al Removal of non-transferrin-bound iron from blood with iron overload using a device with immobilized desferrioxamine. J Med. 1999;30:211-24.

Key Words: AKI, hepcidin-25, iron, serum ferritin, transferrin saturation 
TABLE E1. Patient characteristics of the final study population versus patients excluded for missed bio-banking

\begin{tabular}{|c|c|c|c|}
\hline Characteristic & Study population $(\mathrm{n}=301)$ & Excluded patients $(n=58)$ & $P$ value \\
\hline \multicolumn{4}{|l|}{ Preoperative } \\
\hline Age (y) & $67(60-72)$ & $68(61-74)$ & .183 \\
\hline Male & $225(75 \%)$ & $44(76 \%)$ & .86 \\
\hline Baseline eGFR (mL/min/1.73 m²) & $78(63-93)$ & $80(63-96)$ & .34 \\
\hline Baseline $\mathrm{Cr}(\mathrm{mg} / \mathrm{dL})$ & $85(72-102)$ & $80(65-109)$ & .32 \\
\hline Thakar score & $2(1-3)$ & $2(1-3)$ & .46 \\
\hline Diabetes mellitus & $101(34 \%)$ & $18(31 \%)$ & .71 \\
\hline Chronic obstructive pulmonary disease & $24(8 \%)$ & $5(9 \%)$ & .80 \\
\hline Congestive heart failure & $31(10 \%)$ & $9(16 \%)$ & .25 \\
\hline Previous myocardial infarction & $109(36 \%)$ & $19(33 \%)$ & .62 \\
\hline Previous $\mathrm{CABG}$ & $9(3 \%)$ & $1(2 \%)$ & 1.00 \\
\hline Peripheral arterial disease & $25(8 \%)$ & $5(9 \%)$ & 1.00 \\
\hline Amputation or peripheral arterial disease bypass & $2(1 \%)$ & $0(0 \%)$ & - \\
\hline Previous cerebrovascular accident & $16(5 \%)$ & $3(5 \%)$ & 1.00 \\
\hline Previous transient ischemic attack & $10(3 \%)$ & $1(3 \%)$ & 1.00 \\
\hline Type of surgery (isolated CABG) & $188(62 \%)$ & $35(60 \%)$ & .76 \\
\hline \multicolumn{4}{|l|}{ Intraoperative } \\
\hline Pump time (min) & $95(74-132)$ & $92(71-138)$ & .64 \\
\hline Crossclamp time (min) & $64(45-92)$ & $63(40-93)$ & .64 \\
\hline Operating room duration (min) & $260(216-338)$ & $262(195-326)$ & .27 \\
\hline Intraoperative urine output $(\mathrm{mL})$ & $620(450-955)$ & $573(420-965)$ & .76 \\
\hline
\end{tabular}

Values expressed as median (IQR) or frequency (percent). Continuous variables compared using Mann-Whitney $U$ test, and categoric variables compared using chi-square test. $e G F R$, Estimated glomerular filtration rate; $C r$, creatinine; $C A B G$, Coronary artery bypass grafting.

TABLE E2. Sensitivity and specificity cutoffs for acute kidney injury

\begin{tabular}{lccc}
\hline \multicolumn{1}{c}{ Probability cutoff } & Sensitivity & Specificity & $\begin{array}{c}\text { Youden's } \\
\text { J statistic }\end{array}$ \\
\hline Intraoperative model & & & \\
$0 \%$ & 1.00 & 0.00 & 0.00 \\
$10 \%$ & 0.73 & 0.60 & 0.35 \\
$20 \%$ & 0.55 & 0.86 & 0.41 \\
$\mathbf{2 4} \%$ (maximum cutoff) & $\mathbf{0 . 5 3}$ & $\mathbf{0 . 9 2}$ & $\mathbf{0 . 4 5}$ \\
$30 \%$ & 0.43 & 0.94 & 0.37 \\
$40 \%$ & 0.25 & 0.98 & 0.23 \\
$50 \%$ & 0.20 & 0.99 & 0.19 \\
$60 \%$ & 0.15 & 0.99 & 0.14 \\
$70 \%$ & 0.05 & 1.00 & 0.05 \\
$80 \%$ & 0.03 & 1.00 & 0.03 \\
$90 \%$ & 0.03 & 1.00 & 0.03 \\
$100 \%$ & 0.00 & 1.00 & 0.00 \\
Postoperative model & & & \\
$0 \%$ & 1.00 & 0.00 & 0.00 \\
$\mathbf{1 0} \%$ (maximum cutoff) & $\mathbf{0 . 7 8}$ & $\mathbf{0 . 6 3}$ & $\mathbf{0 . 4 1}$ \\
$20 \%$ & 0.55 & 0.84 & 0.39 \\
$30 \%$ & 0.43 & 0.94 & 0.37 \\
$40 \%$ & 0.33 & 0.97 & 0.30 \\
$50 \%$ & 0.20 & 1.00 & 0.20 \\
$60 \%$ & 0.15 & 1.00 & 0.15 \\
$70 \%$ & 0.05 & 1.00 & 0.05 \\
$80 \%$ & 0.05 & 1.00 & 0.05 \\
$90 \%$ & 0.05 & 1.00 & 0.05 \\
$100 \%$ & 0.00 & 1.00 & 0.00 \\
\hline
\end{tabular}

Intraoperative Model: Thakar score $+1 \mathrm{~h} \mathrm{CPB}$ serum ferritin $+1 \mathrm{~h}$ CPB transferrin saturation. Postoperative Model: Thakar score $+1 \mathrm{~h} \mathrm{CPB}$ serum ferritin $+1 \mathrm{~h} \mathrm{CPB}$ transferrin saturation + urine hepcidin-25. Bold indicates maximum cutoff by Youden's J statistic. 
TABLE E3. Correlation matrix of iron handling variables at 1-hour cardiopulmonary bypass (Spearman's rank correlation coefficient)

\begin{tabular}{lccc}
\hline \multicolumn{1}{c}{ Variable } & $\begin{array}{c}\text { Serum } \\
\text { ferritin }\end{array}$ & $\begin{array}{c}\text { Urine } \\
\text { hepcidin-25 }\end{array}$ & $\begin{array}{c}\text { Transferrin } \\
\text { saturation }\end{array}$ \\
\hline Serum ferritin & - & $\rho=.19$ & $\rho=.27$ \\
Urine hepcidin-25 & $\rho=.19$ & - & $\rho=.19$ \\
Transferrin saturation & $\rho=.27$ & $\rho=.19$ & - \\
\hline
\end{tabular}

Spearman's rank correlation coefficients ( $\rho$ ) demonstrate relationship between variables. Multiple linear regression with AKI as a continuous variable was used to determine multicollinearity. Variables were considered highly correlated if $|\rho|>.7$ and collinear if the variance inflation factor was $>10$.
TABLE E4. Multivariable analyses and model performance of iron-sequestering proteins for acute kidney injury prediction, excluding patients who developed Kidney Disease Improving Global Outcomes acute kidney injury before postoperative day $1, \mathbf{n}=295$

\begin{tabular}{|c|c|c|c|c|}
\hline \multicolumn{2}{|l|}{ Model type } & OR & $95 \%$ CI & $P$ value \\
\hline \multicolumn{5}{|l|}{ Postoperative model } \\
\hline \multicolumn{2}{|l|}{ Thakar score } & 1.52 & $1.22-1.89$ & $<.001$ \\
\hline \multicolumn{2}{|c|}{ Serum ferritin (per $100 \mu \mathrm{g} / \mathrm{L}$ ) } & 0.61 & $0.41-0.92$ & .017 \\
\hline \multicolumn{2}{|c|}{ Transferrin saturation (per 10\%) } & 1.22 & $0.86-1.71$ & .27 \\
\hline \multicolumn{2}{|c|}{ Urine hepcidin-25 (per $1000 \mu \mathrm{g} / \mathrm{L}$ ) } & 0.66 & $0.44-0.98$ & .039 \\
\hline \multicolumn{2}{|l|}{ Diagnostic test } & & \multicolumn{2}{|c|}{ Postoperative model } \\
\hline \multicolumn{2}{|l|}{ Global $P$ value } & & \multicolumn{2}{|c|}{$<.001$} \\
\hline \multicolumn{2}{|l|}{ Discrimination, AUC $(95 \% \mathrm{CI})$} & & \multicolumn{2}{|c|}{$0.81(0.73-0.87)$} \\
\hline \multicolumn{2}{|l|}{ AIC } & & \multicolumn{2}{|c|}{173.7} \\
\hline \multicolumn{2}{|l|}{ Goodness of fit* ( $P$ value $)$} & \multicolumn{3}{|c|}{$11.84(.158)$} \\
\hline \multicolumn{2}{|l|}{ Sensitivity } & \multicolumn{3}{|c|}{0.59} \\
\hline \multicolumn{2}{|l|}{ Specificity } & \multicolumn{3}{|c|}{0.84} \\
\hline $\begin{array}{l}\text { Postoperative model vs } \\
\text { base model comparison }\end{array}$ & Value & & $\mathbf{9 5} \% \mathbf{C I}$ & $P$ value \\
\hline$\triangle \mathrm{AUC}$ & 0.08 & & $(0.02-0.13)$ & .009 \\
\hline Net Reclassification Index & 0.08 & & $(0.02-0.14)$ & .006 \\
\hline IDI & 0.06 & & $(0.01-0.11)$ & .030 \\
\hline
\end{tabular}

$O R$, Odds ratio; $C I$, confidence interval; $A U C$, area under the curve; $A I C$, Akaike Information Criterion; $\triangle A U C$, change in area under the receiver operating characteristic; IDI, integrated discrimination improvement. *Hosmer-Lemeshow test statistic. Maximum cutoff used to generate sensitivity and specificity. Preoperative Base Clinical Model: Thakar score. Intraoperative Model: Thakar score $+1 \mathrm{~h} \mathrm{CPB}$ serum ferritin $+1 \mathrm{~h}$ CPB transferrin saturation. Postoperative Model: Thakar score $+1 \mathrm{~h} \mathrm{CPB}$ serum ferritin $+1 \mathrm{~h}$ CPB transferrin saturation + urine hepcidin-25. 